\title{
Prune-belly syndrome detected by ultrasound in the first trimester and the usefulness of vesicocentesis as a modality of treatment
}

\author{
Mina Byon, Gwang Jun Kim \\ Department of Obstetrics and Gynecology, Chung-Ang University College of Medicine, Seoul, Korea
}

Prune-belly syndrome may be related to lower urinary tract obstruction (LUTO). LUTO in the early gestational age exacerbates fetal renal function and may require intrauterine intervention. If early developed LUTO causes bladder distension and abdominal musculature deficiency, it will result in prune belly syndrome. Therefore, early detection of the disease and proper treatment before the renal impairment is important. However, there are few literatures concerning the treatment of prune belly syndrome in the first trimester. We report a case of prune belly syndrome diagnosed at $11+6$ weeks of gestation and the value of vesicocentesis as a modality of treatment. Ultrasound showed dilated fetal bladder and vesicocentesis was successful in reducing the volume of the bladder. However, the pregnancy was terminated upon request.

Keywords: Cryptorchidism; Eagle-Barrett syndrome; Fetal percutaneous bladder puncture; Genitourinary malformation; Prune-belly syndrome

\section{Introduction}

Prune-belly syndrome is a rare disease that occurs about 1 per 50,000 live births and more than $90 \%$ of the affected patients are male [1]. Early diagnosis and appropriate management before renal compromise is essential for better prognosis. There are few literatures concerning the diagnosis of prune belly syndrome in the first trimester [2-4]. We present a case of an early diagnosed prune belly syndrome and the usefulness of vesicocentesis instead of vesicoamniotic shunt.

\section{Case report}

A 36-year-old woman (gravida 1, para 0) at gestational age of $11+6$ weeks was transferred to our hospital for further evaluation of the suspected fetal abdominal cyst. She had been diagnosed with diabetes mellitus 2 years before and had regular insulin injections. Otherwise, she had neither familial nor past medical history. Ultrasonography at our hospital confirmed enlarged fetal bladder with the size of $2.7 \times 2.5 \mathrm{~cm}$ (Fig. 1) but the classic 'key hole sign' was absent. Other fetal biometric values were appropriate for the gestational age; crown rump length (CRL) $45 \mathrm{~mm}$, neural tube (NT) $0.7 \mathrm{~mm}$.

Chorionic villus sampling resulted in 46, XY karyotype. Based upon informed consent, vesicocentesis with 22-gauge spinal needle was performed under ultrasonographic guidance (Voluson E8, GE Medical Systems Kretztechnik GmbH \& Co. OHG, Zipf, Austria). The aspirated fetal urine was analyzed. As fetal bladder was not enlarged again until 1 week after

Received: 2012.12.18. Revised: 2013.3.11. Accepted: 2013.3.11. Corresponding author: Gwang Jun Kim

Department of Obstetrics and Gynecology, Chung-Ang University Hospital, Chung-Ang University College of Medicine,

102 Heukseok-ro, Dongjak-gu, Seoul 156-755, Korea

Tel: +82-2-6299-1656 Fax: +82-2-6263-2187

E-mail: gjkim@cau.ac.kr

*This case was previously reported as a view only poster presentation (P34.06) at the 20th World Congress on Ultrasound in Obstetrics and Gynecology, 10-14 October 2010, Prague, Czech Republic.

Articles published in Obstet Gynecol Sci are open-access, distributed under the terms of the Creative Commons Attribution Non-Commercial License (http://creativecommons. org/licenses/by-nc/3.0/) which permits unrestricted non-commercial use, distribution, and reproduction in any medium, provided the original work is properly cited.

Copyright $\odot 2013$ Korean Society of Obstetrics and Gynecology 


\title{
Obstetrics \& Gynecology Science
}

\author{
Vol. 56, No. 4, 2013
}
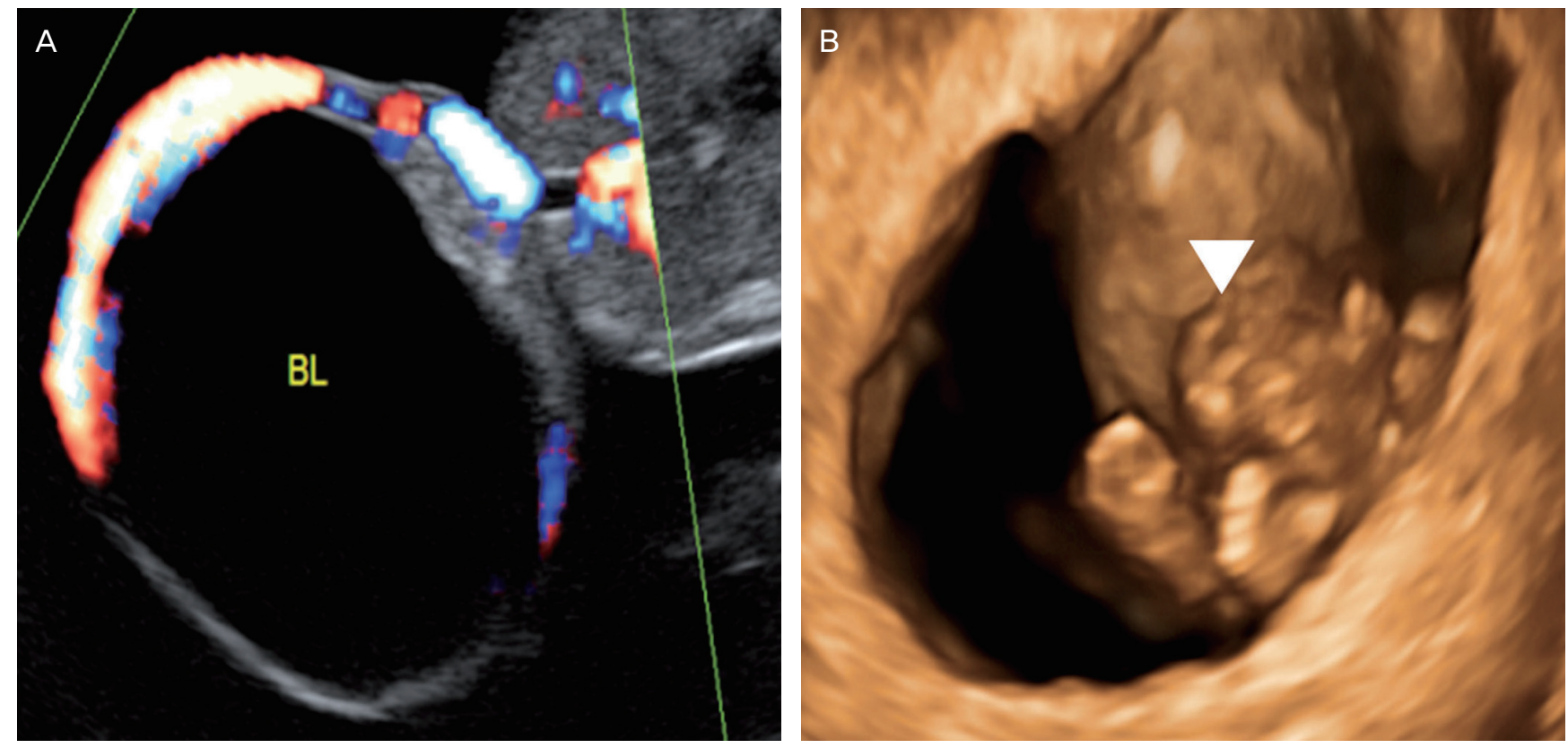

Fig. 1. Fetal bladder $(A)$ dilated fetal bladder $(B L)$ around which umbilical arteries are shown (color Doppler), bladder size $2.7 \times 2.5 \mathrm{~cm}$. $(B)$ Collapsed fetal bladder (arrow head) after vesicocentesis.

vesicocentesis, the procedure seemed to be effective. However, the pregnancy was interrupted because the patient and her husband changed their mind and strongly requested termination of pregnancy. Postmortem gross examination confirmed prenatal ultrasooographic diagnosis. Besides, undiagnosed anomalies were identified; bilateral cleft lip, cleft palate, bilateral club feet, and polydactyly (Fig. 2).

\section{Discussion}

Prune-belly syndrome, also called Eagle-Barrett syndrome is a rare congenital malformation. The clinical manifestations are [1] deficiency of abdominal wall muscles [2], cryptorchidism in male fetus [3] genitourinary malformations. The pathogenesis of prune belly syndrome is not yet fully understood. Some theories have been suggested; urinary tract obstruction, maldevelopment of the mesoderm, genetic deficit, and abnormalities of allantois [4]. Prune belly syndrome is also associated with pulmonary, cardiovascular, gastrointestinal and musculoskeletal abnormalities [5]. In our case, postmortem examination revealed cleft lip and palate, club feet and polydactyly. Although cryptorchidism was not so evident because of early geatational age, the key hole sign was not found. Therefore it would be diagnosed as prune belly syndrome with the exclu- sion of other urinary tract anomalies.

Prune belly syndrome is classified into 3 groups by antenatal and anatomical features $[5,6]$. Among them, category I is characterized by pulmonary hypoplasia, pneumothorax, oligohydramnios, renal dysplasia, urethral obstruction patent urachus or club feet. The prognosis is worst in the type I group. Although pulmonary hypoplasia was not clearly identified in the very early gestational age, the fetus with club feet would belong to the category I.

Fetal urine production begins between 8 and 10 gestational weeks and fetal bladder can be identified by ultrasound at least from 11 weeks. Therefore the detection of prune belly syndrome by ultrasound in the very early gestational period is uncommonly reported [2-4]. It is noteworthy that, in our case, very large bladder was identified and the fetus was diagnosed as prune belly syndrome by prenatal abdominal ultrasound before 12 weeks of gestational age.

Hypotonic urine is associated with a better prognosis [7] and kidney functions normally when the urinary concentration of sodium is lower than $50 \mathrm{mmol} / \mathrm{L}$ [8]. Early onset of bladder distension and hypertonic urine result in worse prognosis. In our case, the urine analysis revealed hypertonic urine and the concentration of sodium was over $120 \mathrm{mmol} / \mathrm{L}$. This implies that renal function was deteriorated in the very early gestational age. However urine analysis before 20 weeks of gesta- 


\section{Obstetrics \& Gynecology Science}

Mina Byon, et al. First trimester prune belly syndrome
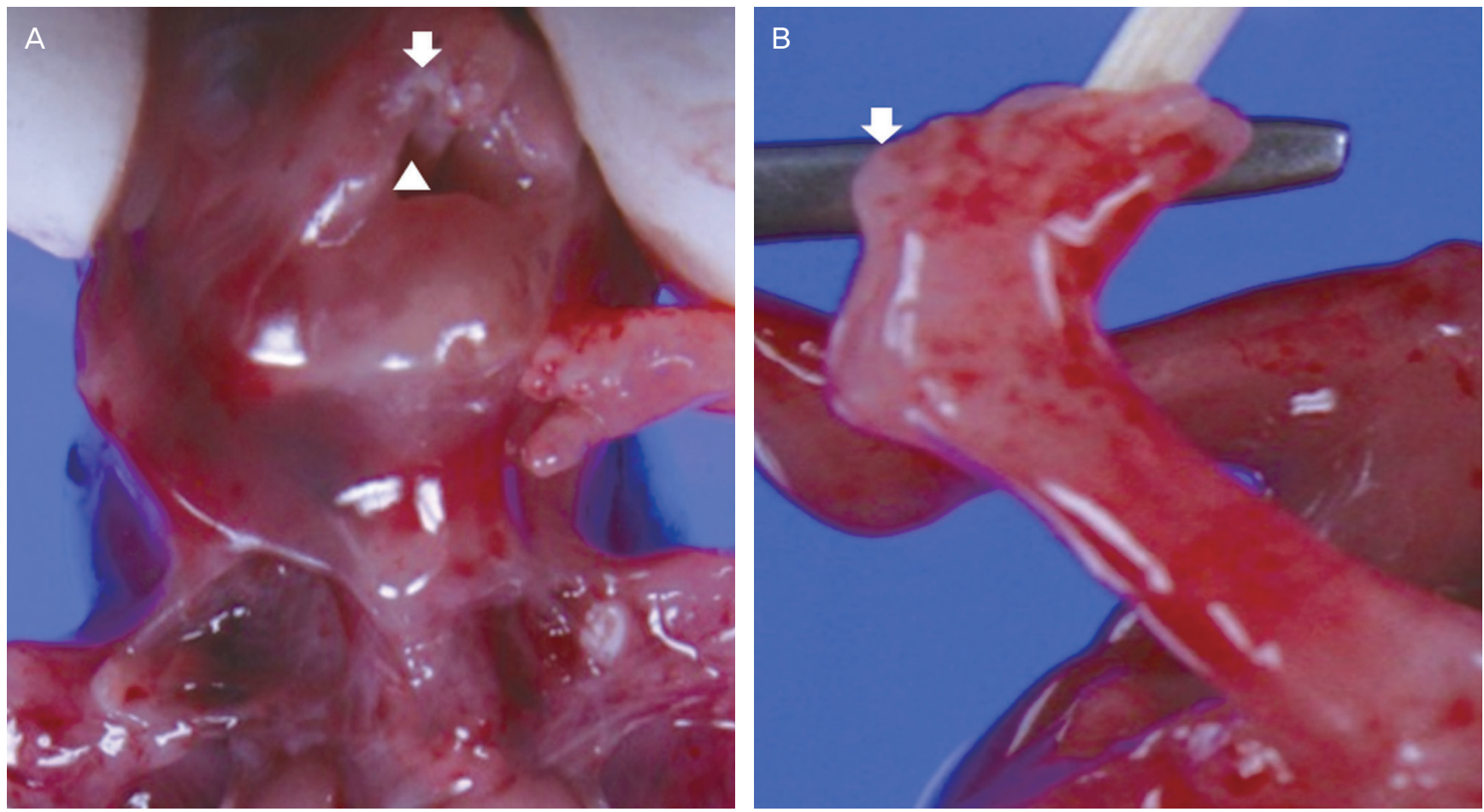

Fig. 2. Postmortem appearance. (A) Cleft lip (arrow) and palate (arrow head). (B) Polydactyly (arrow).

tion may be inaccurate.

As renal function compromise is a factor that determines the prognosis, prenatal intervention is needed to preserve renal function and to provide the aqueous environment for lung maturation $[9,10]$. Various management modalities can be applied; regular sonographic monitoring of the urinary tract and amniotic fluid volume in utero, fetal, vesicoamniotic shunting, termination of pregnancy, or early delivery so long as the neonatal viability is achieved.

Vesicoamniotic shunt for urinary obstruction can prevent pulmonary hypoplasia and renal dysplasia or even may improve postnatal quality of life. Early intervention can lead to better results $[11,12]$. However, vesicoamniotic shunt is not possible in the very early gestational age as in our case because the fetus is too small for the shunt instrument. In addition, the relatively wide location of placenta and frequent fetal position can be obstacles to vesicoamniotic shunt [13]. However, early intervention would be crucial before deterioration of renal function, especially for early complete urethral obstruction just as our case.

Vesicocentesis for the treatment of fetal megacystis and prune belly syndrome have been reported [14]. We performed vesicocentesis by spinal needle under ultrasound guidance.
It was so effective as to reduce the bladder volume without severe complications.

Although the pregnancy in this case was terminated upon parental request, this study suggests the importance of the early diagnosis of the disease and the prompt intervention to improve prognosis. Our case is one of the earliest diagnoses and managements of prune-belly syndrome. Furthermore, the vesicocentesis with finer needle may be used as an effective treatment modality for the lower urinary tract obstruction developed in the first trimester.

\section{Conflict of interest}

No potential conflict of interest relevant to this article was reported.

\section{References}

1. Herman TE, Siegel MJ. Prune belly syndrome. J Perinatol 2009;29:69-71.

2. Yamamoto H, Nishikawa S, Hayashi T, Sagae S, Kudo 


\section{Obstetrics \& Gynecology Science}

Vol. 56, No. 4, 2013

R. Antenatal diagnosis of prune belly syndrome at 11 weeks of gestation. J Obstet Gynaecol Res 2001;27:37-40.

3. Hoshino $T$, Ihara $Y$, Shirane $H$, Ota T. Prenatal diagnosis of prune belly syndrome at 12 weeks of pregnancy: case report and review of the literature. Ultrasound Obstet Gynecol 1998;12:362-6.

4. Papantoniou N, Papoutsis D, Daskalakis G, Chatzipapas I, Sindos M, Papaspyrou I, et al. Prenatal diagnosis of prune-belly syndrome at 13 weeks of gestation: case report and review of literature. J Matern Fetal Neonatal Med 2010;23:1263-7.

5. Hassett S, Smith GH, Holland AJ. Prune belly syndrome. Pediatr Surg Int 2012;28:219-28.

6. Woodard JR. The prune belly syndrome. Urol Clin North Am 1978;5:75-93.

7. Crombleholme TM, Harrison MR, Golbus MS, Longaker MT, Langer JC, Callen PW, et al. Fetal intervention in obstructive uropathy: prognostic indicators and efficacy of intervention. Am J Obstet Gynecol 1990;162:1239-44.

8. Defoort $P$, Thiery M. Assessment of the indication for intrauterine treatment of urinary tract malformations. J Perinat Med 1988;16:175-81.
9. Yiee J, Wilcox D. Abnormalities of the fetal bladder. Semin Fetal Neonatal Med 2008;13:164-70.

10. Leeners B, Sauer I, Schefels J, Cotarelo CL, Funk A. Prune-belly syndrome: therapeutic options including in utero placement of a vesicoamniotic shunt. J Clin Ultrasound 2000;28:500-7.

11. Biard JM, Johnson MP, Carr MC, Wilson RD, Hedrick HL, Pavlock C, et al. Long-term outcomes in children treated by prenatal vesicoamniotic shunting for lower urinary tract obstruction. Obstet Gynecol 2005;106:503-8.

12. Shimada K, Hosokawa S, Tohda A, Matsumoto F, Johnin $K$. Histology of the fetal prune belly syndrome with reference to the efficacy of prenatal decompression. Int J Urol 2000;7:161-6.

13. Galati V, Beeson JH, Confer SD, Frimberger D, Campbell JB, Ramji FG, et al. A favorable outcome following 32 vesicocentesis and amnioinfusion procedures in a fetus with severe prune belly syndrome. J Pediatr Urol 2008;4:170-2.

14. Carroll SG, Soothill PW, Tizard J, Kyle PM. Vesicocentesis at 10-14 weeks of gestation for treatment of fetal megacystis. Ultrasound Obstet Gynecol 2001;18:366-70. 